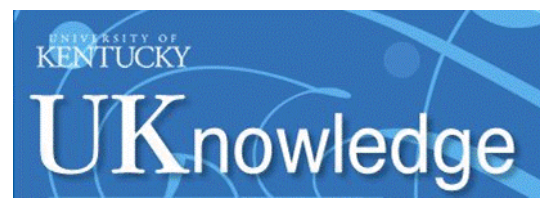

University of Kentucky

UKnowledge

\title{
Improved Continuation Rate of Depot-Medroxyprogesterone Acetate in Adolescent Mothers
}

Hatim A. Omar

University of Kentucky, hatim.omar@uky.edu

Amy Fowler

University of Kentucky

Sandy D'Angelo

University of Kentucky

Follow this and additional works at: https://uknowledge.uky.edu/pediatrics_facpub

Part of the Pediatrics Commons

Right click to open a feedback form in a new tab to let us know how this document benefits you.

\section{Repository Citation}

Omar, Hatim A.; Fowler, Amy; and D'Angelo, Sandy, "Improved Continuation Rate of Depot-

Medroxyprogesterone Acetate in Adolescent Mothers" (2002). Pediatrics Faculty Publications. 84.

https://uknowledge.uky.edu/pediatrics_facpub/84

This Article is brought to you for free and open access by the Pediatrics at UKnowledge. It has been accepted for inclusion in Pediatrics Faculty Publications by an authorized administrator of UKnowledge. For more information, please contact UKnowledge@lsv.uky.edu. 


\section{Improved Continuation Rate of Depot-Medroxyprogesterone Acetate in Adolescent Mothers}

Digital Object Identifier (DOI)

http://dx.doi.org/10.1515/IJAMH.2002.14.2.149

\section{Notes/Citation Information}

Published in International Journal of Adolescent Medicine and Health, v. 14, no. 2, p. 149-152.

(C) Freund Publishing House Ltd.

The copyright holder has granted permission for posting the article here. 


\title{
Improved continuation rate of Depot-Medroxyprogesterone acetate in adolescent mothers
}

\author{
Ilatim Omar, MD, Amy Fowler and Sandy D'Angelo, $\mathrm{PhD}$
}

Secrion of Adolescent Medicine, Department of Pediatrics, University of Kentucky, Lexington. United States of America

Absrace: Poor compliance and high discontinuation rates of Depot-Medroxyprogesterone Acetate (DNIPA) and other contraceptive methods are major factors in the continuing problem of adolescent pregenancy. In this study we attempted to determine if providing comprehensive health care for teen mothers and their babies would improve continuation rates of DMPA. Patients who started DMPA between 1/1/96 and 1/1/99 were included. Teen mothers and their babies received all their health care in this clinic. supported by State funding. Key elements regarding DMPA in this clinic were continuity of care. phone and mail reminders of appointments, free DMPA for patients without insurance, counscling at cach visit and available evening clinic. In the study period a total of 299 (age 13.22 jears) patients were started on DMPA. Fifty-one percent were white, $47 \%$ black and $2 \%$ others. Sixty-three percent were single, $20 \%$ married, $3 \%$ cohabitating and $14 \%$ undetermined (missing data). Seventy-eight percent had one baby and $22 \%$ more than one. A total of 189 patients (63.2\%) continued to be compliant after one year of use and 101 patients (33.8\% of total) continued beyond the second year. The most common side effect reported was bleeding or spotting (32\%), However only seven patients $(2.3 \%)$ discontinued use because of it. It is concluded that continuity of care (same staft and providers on each visit), regular counseling, flexible hours (evening appointments), financial case (free DMPA and no visit charge for those without insurance), combined Teen-Tot health visits and regular reminders of appointments may help improve compliance and continuation rates in teen mothers leading to better success in preventing repeat teen pregnancy.

Romords: Adolescence, adolescent contraception, injectable progesterone, Depot Provera, teenage mothers, United States

Corrapondence: Hatim Omar, MD, Associate Professor, Director of Adolescent Medicine and Young Parent programs, J422, Kentucky Clinic, University of Kentucky, Lexington, KY 40536-0284, United States. Tel: 859-323-6426 ext. 307, Fax. 859-257-7706, E-mail: haomar2@pop.uky.edu

Submined: January 11, 2002. Revised: January 18, 2002. Accepted: January 19, 2002.

\section{INTRODUCTION}

In a recent prospective study in adult women, continuation rates for DMPA were reported to be $68 \%, 67 \%, 55 \%$ and $51 \%$ at 3. 6. 9 and 12 months respectively (1). Previous studies showed various 12-month continuation rates, ranging from 23 to $61 \%$ (2-6). In adolescents, DMPA continuation reses are even lower $(7,8)$. Pretreatment counseling was found to enhance complience and improve continuation rates of DNSPA use (9). Other factors related to the providers approach to the patient also played a role in continuation of DMPA (1). Menstrual changes are usually the most common reasons for discontinuation of the method $(1,9)$. In this study, we reviewed the clinical data in regard to DMPA in our Young Parent Program in order to assess continuation rates.

\section{METHODS}

A retrospective review of clinic data in regard to DMPA use and continuation was 
done. Patients started on DMPA on or after 1/1/1996 were included. Total number of patients included in the study was 299. See Table 1 for demographics. The Young Parents Program Clinic in which these patients are enrolled provides comprehensive services that are different from most conventional primary care clinics. The Young Parents Program Clinic:

- Provides comprehensive care: for both teen mother and her baby. This includes preventive care, reproductive services, mental health and acute care visits. We also provide care for siblings of the teen as well as family counseling.

- Continuity of care: patients are seen by the same staff and attending physicians on each visit.

- Flexible hours: including evening clinic to allow teens to attend school or work during the day.

- Financial incentives: patients with no insurance are given DMPA free of charge and no visit charge is applied if they cannot afford it.

- Counseling is provided prior to the start of any birth control method and at each visit.

- Telephone and/or mail reminders of clinic appointments are routinely utilized.

Table 1. Demographic characteristics of patients included in the study.

\begin{tabular}{ll} 
Mean Age & 17.75 years \\
Standard Deviation & 1.56 years \\
Median & 17.94 years \\
Age Range & $13-22$ years \\
White & $51 \%$ \\
Black & $47 \%$ \\
Others & $2 \%$ \\
Single & $63 \%$ \\
Married & $20 \%$ \\
Cohabitating & $3 \%$ \\
Undetermined & $14 \%$ \\
Dar- 1 & $78 \%$ \\
$\quad 1>1$ & $22 \%$ \\
\hline
\end{tabular}

\section{RESULTS}

Continuation: rate of DMPA after 12 months was $63.2 \%$. $33.8 \%$ of patients were still using DMPA at 24 months and 15\% are still continuing after 36 months. This percentage rate at 36 months would probably be higher when patients of more than 24 and less than 36 months are added. Seven percent of patients have completed 48 months. The most common adverse side effect reported was spotting or bleeding, which was present in $32 \%$ of patients, however only seven patients (2.3\%) patients discontinued use because of it.

Other-side effects such as headaches, mood changes and weight gain were reported in $2 \%, 4 \%$ and $31 \%$ respectively, but were addressed during each visit and counseling and education provided. None of the patents discontinued use because of these side effects. A desired side effect for many patients was amenorrhea, which was present in $47 \%$ of patients. It was not listed as an adverse side effect, since many patients considered it a convenience rather than an annoyance.

\section{DISCUSSION}

This study looked at a special group of patients in a special setting. The Young Parents Program is one of the few programs in the country that provides care to the mother and baby at the same time. Many adolescent mothers are more likely to miss an appointment for themselves, but are more compliant when it comes to their babies. Having simultaneous appointments allows these patients to save time and effort as well as financial savings related to transportation expenses and missing work or school.

Another factor that helps compliance is the evening clinic, which allows these patients to avoid problems with their work or school. A significant positive influence on the patients is the continuity of care, which puts them at ease and makes it easier 
to ask questions and to call if they have any doubts about their birth control or any other issue. All visits are physician visits with education and counseling provided prior to the start on DMPA and on each consecutive visit. Counseling usually provides detailed and honest information on all possible health benefits as well as adverse effects, which also helps compliance as in other studies (1). Many adolescents, just as adults, tend to forget appointments especially when they are 2-3 months away. In our clinic a dual system of telephone and mail reminders is utilized and a simultaneous appointment for both mother and baby is provided almost always. In addition, our patient population can obtain all health care needs in the clinic, including mental health counseling and treatment allowing even more reduction of lost time and effort moving from clinic to clinic to obtain different services.

Most adolescent mothers have some degree of financial difficulty that interferes with their access to health care as well as their compliance. In our clinic financial counseling is also routinely provided to help patients utilize available State and Federal resources for health insurance and when neither is available, visit and medication charges are waved. All these factors are responsible for the much higher rate of compliance noted here compared to previous reports (1-8).

It has been reported that menstrual disturbances were the main culprits for discontinuation of DMPA $(1,9)$. In this study, bleeding was responsible for discontinuation in only seven patients $(2.3 \%)$ that had heavy bleeding. Most patients with spotting and intermittent bleeding were able to continue DMPA use.

\section{CONCLUSION}

Continuity of care, regular counseling, flexible hours, financial incentives, combined teen-tot visits and regular reminders of appointments may help to improve DMPA continuation rates in teen mothers, which leads to reduction in repeat pregnancy.

\section{ACKNOWLEDGEMENTS}

This study was presented in part at the $15^{\text {th }}$ annual meeting of the North American Society of Pediatric and Adolescent Gynecology, Toronto, Canada, May 18-20, 2001.

\section{REFERENCES}

1. Hubacher D, GocoN, Gonzalez B, Taylor D. Factors affecting continuation rates of DMPA. Contraception 2000;60: 345-51.

2. Westhoff C. Depot medroxyprogesterone acetate contraception. Metabolic parameters and mood changes. J Reprod Med 1994; 41(suppl5):401-6.

3. O'Dell CM, Forke CM, Polaneczky MM, et al. Depot medroxyprogesterone acetate or oral contraception in postpartum adolescents. Obstet Gynecol 1998;91:609-14.

4. Potter LS, Dalberth BT, Canamar R, Betz $M$. Depot medroxyprogesterone acetate pioneers. A retrospective study at a North Carolina Health Department. Contraception 1997;56:305-12.

5. Davidson AR, Kalmuss D, Cushman LF, et al. Injectable contraceptive discontinuation and subsequent unintended pregnancy among low-income women. Am J Public Health 1997;87: 1532-4.

6. Sekadde-Kigondu C, Mwathe EG, Ruminjo JK, et al. Acceptability and discontinuation of Depot-medroxyprogesterone Acetate, IUCD and combined pill in Kenya. East Afr Med $J$ 1996;73:786-94.

7. O'Dell C, Forke C, Polaneczky M, et al. Depot-medroxyprogesterone Acetate vs oral contraceptive use in postpartum adolescents. J Adolesc Health 1997;20: 127. Abstract. 
8. Cromer BA, Smith D, Blair JM, et al. A prospective study of adolescents who choose among Levonorgestrel Implant (Norplant), Medroxyprogesterone acetate (Depot-medroxyprogesterone Acetate), or the combined oral contraceptive pill as contraception. Pediatrics 1994;94:687-94.
9. Lei ZW, Wu SC, Garceau RJ, et al. Effect of pretreatment counseling on discontinuation rates in Chinese women given depot-medroxyprogesterone acetate for contraception. Contraception 1996; 53:357-61.

\section{BITS N PIECES}

Financial cost of social exclusion: follow up study of antisocial children into adulthood

Objectives: To compare the cumulative costs of public services used through to adulthood by individuals with three levels of antisocial behaviour in childhood.

Design: Costs applied to data of 10 year old children from the inner London longitudinal study selectively followed up to adulthood.

Setting: Inner London borough.

Participants: 142 individuals divided into three groups in childhood: no problems, conduct problems, and conduct disorder.

Main outcome measures: Costs in 1998 prices for public services (excluding private, voluntary agency, indirect, and personal costs) used over and above basic universal provision.

Results: By age 28, costs for individuals with conduct disorder were 10.0 times higher than for those with no problems ( $95 \%$ confidence interval of bootstrap ratio 3.6 to 20.9) and 3.5 times higher than for those with conduct problems (1.7 to 6.2).

Mean individual total costs were $£ 70019$ for the conduct disorder group (bootstrap mean difference from no problem group $£ 62898 ; £ 22692$ to $£ 117896$ ) and £24 324 ( $£ 16707 ; £ 6594$ to $£ 28149$ ) for the conduct problem group, compared with $£ 7423$ for the no problem group. In all groups crime incurred the greatest cost, followed by extra educational provision, foster and residential care, and state benefits; health costs were smaller. Parental social class had a relatively small effect on antisocial behaviour, and although substantial independent contributions came from being male, having a low reading age, and attending more than two primary schools, conduct disorder still predicted the greatest cost.

Conclusions: Antisocial behaviour in childhood is a major predictor of how much an individual will cost society. The cost is large and falls on many agencies, yet few agencies contribute to prevention, which could be cost effective.

Scott S, Knapp M, Henderson J, Maughan B. BMJ 2001;323:191. 